\title{
Haematological, Liver Function Parameters and Heavy Metal Assessment of KWMC Workers at Roadside and Mixed Waste Dumpsites in Kwara State, Nigeria
}

\section{1*OGUNDELE, DT; ${ }^{1}$ OLAYEMI, VT, ${ }^{1}$ FOLARANMI, FM; ${ }^{2}$ OLUDELE, OE; ${ }^{3}$ OLADEJO, AA}

\author{
${ }^{1 *}$ Department of Chemical, Geological and Physical Sciences, Kwara State University Malete, Nigeria \\ ${ }^{2}$ Department of Environmental Science, Petroleum Training Institute Warri Delta State, Nigeria \\ ${ }^{3}$ Department of Applied Biochemistry, Nnamdi Azikiwe University, Awka, Anambra State Nigeria. \\ *Corresponding Author Email: oludeledamilola@gmail.com
}

\begin{abstract}
Allergic and health implications associated with gardening and waste-scavenging necessitated this study. Blood samples of 27 waste-workers and 16 non-waste workers (control) were digested and analysed for Lead, Cadmium, Nickel and Chromium. Samples were analysed for haematological parameters White Blood Cell (WBC), neutrophils, lymphocytes, Liver function parameters aspartate amino transferase (AST), alanine amino transferase (ALT), and alkaline phosphatase (ALP). Mixed solid waste samples from dumpsites and road soils were analysed by Atomic Absorption Spectroscopy. $\mathrm{Pb}$ concentrations between $16.0-29.5 \mathrm{mg} / \mathrm{Kg}$ were found in road soils and least $\mathrm{Cd}$ contamination between $0.5-2.0 \mathrm{mg} / \mathrm{Kg}$ were recorded. Insignificant difference in metals deposit in road soils and mixed solid wastes, except for $\mathrm{Pb}$ and $\mathrm{Cd}$ were observed. Least deposited metals $(\mathrm{Cd}, \mathrm{Cr}$ and $\mathrm{Ni}$ ) had approximately same deposit level and the highest metal deposit was $\mathrm{Pb}$. Zero difference existed between $\mathrm{Cr}$ concentrations in blood samples of both groups. However, results showed true difference between baseline $\mathrm{Pb}$ and $\mathrm{Cd}$ concentrations of the groups. Haematological parameters and liver function values showed insignificant difference in the groups. Lead was the highest heavy metal found in road soil, solid-waste worker's blood.
\end{abstract}

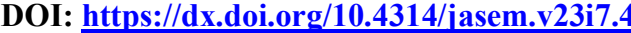

Copyright: Copyright (C) 2019 Ogundele et al. This is an open access article distributed under the Creative Commons Attribution License (CCL), which permits unrestricted use, distribution, and reproduction in any medium, provided the original work is properly cited.

Dates: Received: 24 May 2019; Revised: 27 June 2019; Accepted 12 July 2019

Keywords: Allergic reaction; Heavy metals; Waste management; Haematology.

The properties of heavy metals in urban soils, urban road dusts and agricultural soils are still contemporary. This fact can be said to have been well documented and has enhanced the count up of articles in recent years (Babula et al., 2008). The enhancement is probably attributed to the potential public health risk associated with the intake of heavy metals. Heavy metals in urban soils and urban road dusts can be accumulated in human body via direct inhalation, ingestion and dermal contact absorption (De-Miguel et al., 2007). However, intake of heavy metals via the soil-crop chain has been considered as the predominant pathway of human exposure to environmental heavy metals in agricultural area (Amato et al., 2009). Numerous studies have shown that the pollution sources of heavy metals in environment are mainly traceable to anthropogenic sources. In urban soils and urban road dusts, the anthropogenic sources of heavy metals include traffic emission (vehicle exhaust particles, tire wear particles, weathered street surface particles, brake lining wear particles), industrial emission (power plants, coal combustion, metallurgical industry, auto repair shop, chemical plant, etc.), domestic emission, weathering of building and pavement surface, atmospheric deposit and so on (Faiz et al., 2009; Montagne et al., 2007). However, the anthropogenic sources of heavy metals in agricultural soils include mining, smelting, waste disposal, urban effluent, sewage sludge, pesticides and fertilizers application (Yang et al., 2009). In developing countries, heavy metal pollution in urban soils, urban road dusts and agricultural soils has become severe with the rapid industrialisation and urbanisation and the remediation of these posed health and environmental challenges over the last two decades (Bhargava et al., 2003). Allergic reactions associated with clean up (hypersensitivity to substance) are characterised by excessive activation of certain white blood cells called mast cells and basophil granulocyte by Immunoglobulin E (IgE). This reaction results in an inflammatory response which could range from minor discomfort to life-threatening challenges on the individuals. Many allergens such as dust, wool or pollen are airborne particles. In these cases, symptoms arise in areas in contact with air, such as eyes, nose, and lungs. For instance, allergic rhinitis, also known as hay fever, causes irritation of the nose, sneezing, itching, and redness of the eyes (Rakel and

*Corresponding Author Email: oludeledamilola@gmail.com 
Bope, 2005). Inhaled allergens can also lead to asthmatic symptoms, caused by narrowing of the airways (bronchoconstriction) and increased production of mucus in the lungs, shortness of breath (dyspnea), coughing and wheezing (David, 2009). One of the occupations that bring about exposure to allergens produced by weeds, grasses and trees is gardening and road-soil sweeping. Gardening and sweeping is occupation of many individuals in developing countries to combat the menace of indiscriminate waste dumping. Dust borne heavy metals accumulate in topsoil due to atmospheric deposition by sedimentation, impaction and interception (Sezgin et al., 2006). In general, influences between air and soil pollution are mutual. Just as the atmosphere can transfer a large amount of heavy metals into urban soils through precipitation (Patel et al., 2001) road side dusts can also contribute to the concentration of heavy metals in the air (Nazzal et al., 2014). Several studies have shown that metals such as $\mathrm{Pb}, \mathrm{Cd}, \mathrm{Ni}$, amongst others, are responsible for certain diseases that afflict humans (especially children and street traders who spend up to 10 hours daily selling their goods along the streets) and animals (Wachukwu et al., 2007). Although work has been done on the heavy metal contents of roadside soil and vegetation in north central Nigeria, few or no work has been done on the gardeners and roadsides sweepers in Ilorin, Nigeria.

This study aimed at determining the heavy metal contents in road soil, dumpsites, road-side workers, and the health impact or allergies associated with solid waste management. It also elucidated on the diseases associated or commonly found amongst road-side workers.

\section{MATERIALS AND METHODS}

Nature and Design of Project: Sample preparation and other laboratory procedures were conducted at Chemistry Laboratory, Kwara State University Malete, Nigeria. Haematological and liver function tests were conducted at University of Ilorin Teaching Hospital. The elemental analysis of heavy metal using Atomic Absorption Spectrophotometer (AAS) was carried out at Central Research Laboratory, University of Ilorin, Ilorin, Nigeria and Multidisciplinary Central Research Laboratory, University of Ibadan, Ibadan, Nigeria.

Study Area: Ilorin lies within latitude $8^{\circ} 28^{\prime} \mathrm{N}$ and $8^{\circ} 31^{\prime} \mathrm{N}$ and longitude $4^{\circ} 38^{\prime} \mathrm{E}$ and $4^{\circ} 40^{\prime} \mathrm{E}$ in North Central Nigeria. Ilorin has few but emerging industries, many commercial centres and schools of various levels, hospitals and residential buildings. The main occupation of residents of the town is civil service. Other occupations are farming and trading. This study was carried out on four commercial roads (Maraba, Challenge, Unity and Taiwo) and Global Positioning System (GPS) was used to provide geolocation of these areas. However, no industrial activity was apparent within the vicinity of the sampled locations. Heavy metal assessment was also carried out on two mixed waste dumpsites (Amoyo and Otte).

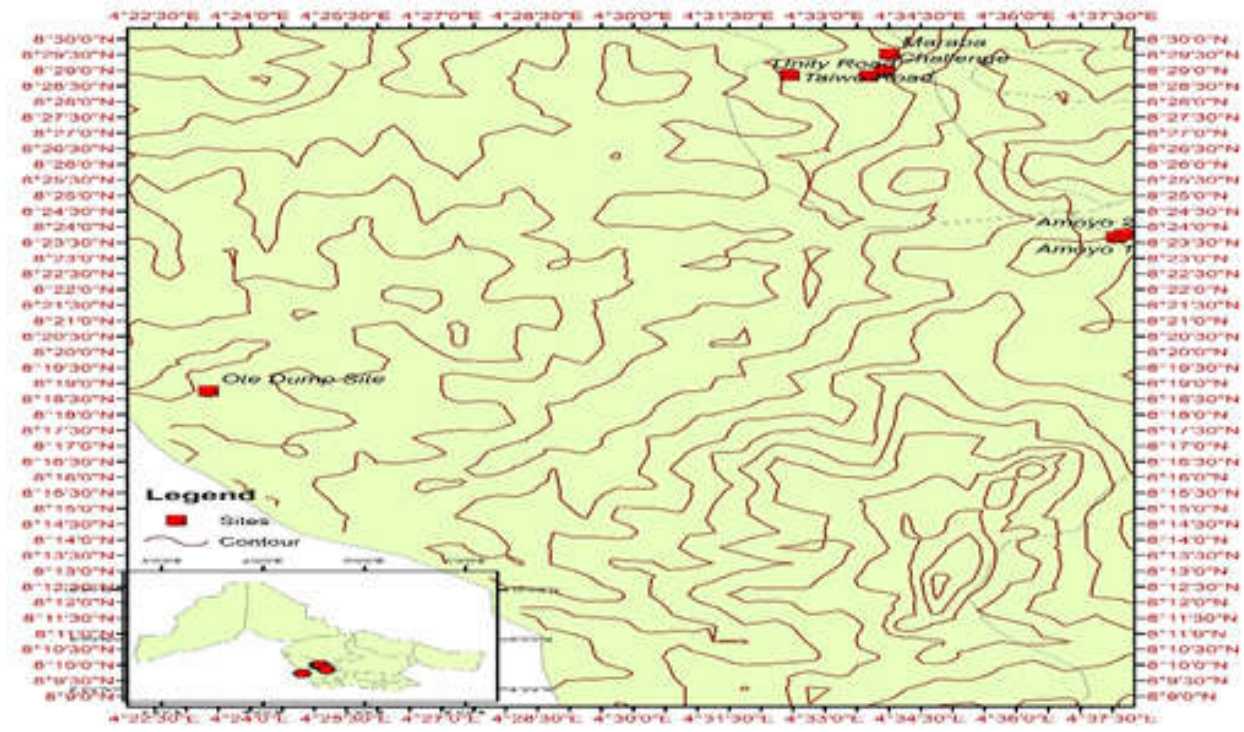

Fig 1. Location map showing sampling points in Kwara State, Nigeria 
Study Population: Informed consent of Kwara State Ministry of Environment and Kwara Waste Management Company (KWMC) waste workers was obtained. The study was carried out using subjects within the age range of 30 to 52 years who had worked as road sweepers and waste disposers for about one to seven years. A total of 43 participants $(27 \mathrm{road}$ sweepers and solid waste workers, and 16 control subjects who were not involved in waste disposal) were involved in the study.

Blood Sample Collection: A standard clean venepuncture technique was used to collect $10 \mathrm{ml}$ of venous blood from each volunteer. $2 \mathrm{~mL}$ of venous blood was dispensed into dipotasium Ethylene Diamine Tetra-Acetic (EDTA) anticoagulant tube and was mixed properly. This sample was used for establishing haematological parameters (WBC and differential count). $3 \mathrm{~mL}$ of the venous blood was also dispensed into lithium heparin anticoagulant tube and mixed thoroughly. The plasma derived from the lithium heparin anticoagulated blood was used for liver function tests (LFTs). The remaining $5 \mathrm{~mL}$ of the venous blood was dispensed into dry plain tubes without any anticoagulant. The sera derived from the plain tubes were used for the determination of concentration of Lead, Nickel, Chromium and Cadmium. All the analyses were done on the same day of sample collection.

Road Soil Sample Collection: Soil samples were randomly collected from both sides and the median of the roads focused in the study by sweeping roadsides and median with a plastic brush into a plastic waste packer and kept in well-sealed polythene sample bags for analysis. Mixed waste samples were collected at Amoyo and Otte waste dump sites by taking a random sample of soil and waste into polyethylene bags for heavy metal analysis.

Digestion of Blood Samples for Heavy Metal Analysis: Blood samples were digested through the Conventional Wet Acid Method. Accurately, $0.5 \mathrm{~mL}$ of whole blood was taken into Pyrex flask separately. To this was added $3 \mathrm{~mL}$ of freshly prepared mixture of concentrated nitric acid and hydrogen peroxide $(2: 1$ $\mathrm{V} / \mathrm{V}$ ) and was made to stand for 10 minutes. The flasks were covered with watch glass and then digested at $60^{\circ} \mathrm{C}$ for 90 minutes. The digests were then treated with $2 \mathrm{~mL}$ nitric acid and few drops of $\mathrm{H}_{2} \mathrm{O}_{2}$ while heating continued on hot plate at $80^{\circ} \mathrm{C}$ until a clear digested solution was obtained. The excess acid mixture was evaporated to semi-dryness, cooled and diluted with $0.1 \mathrm{~mL}$ nitric acid. These were transferred into $100 \mathrm{~mL}$ volumetric flask and made up to mark with distilled water.
Digestion of Road Soil Samples for Heavy Metal Analysis: Road soil samples and soil from mixed waste dump sites were dried for 24 hours at a temperature of $100^{\circ} \mathrm{C}$ and sieved through $0.1 \mathrm{~mm}$ nylon mesh. In addition, $0.5 \mathrm{~g}$ of the fractionated dust and mixed waste soil samples was digested by adding $10 \mathrm{ml} 65 \%$ $\mathrm{HNO}_{3}$ and $2 \mathrm{ml}$ concentrated HF. This was heated to dryness on a water bath. Then $10 \mathrm{ml}$ of $1 \% \mathrm{HNO}_{3}$ was added and heated to boiling and the solution was allowed to cool to room temperature and finally made up to $50 \mathrm{ml}$ (Bada et al., 2001). This was filtered using $<2 \mathrm{~mm}$ Whatsman Filter paper and the sample were taken for elemental analysis using Atomic Absorption Spectrophotometer (AAS).

Analysis of Samples: All the human blood samples were analysed based on haematological parameters using Dacie and Lewis methods. For the liver function tests (LFTs), a single cell visible spectrophotometer with a continuous wavelength range from 335 to 1000 $\mathrm{nm}$ was used for determination of the individual concentration of each of the liver function test. The digested sample solutions (blood, road soil and mixed waste from dumpsites) were then analysed for the heavy metals using Atomic Absorption Spectrophotometer. The Atomic Absorption Spectrophotometer provides accurate quantitative analysis of metals in blood, water, soil, sediments or rocks.

Data Analysis: All obtained data were analyzed statistically using student's t-test, correlation coefficient and Kruskal-Wallis rank sum test.

\section{RESULTS AND DISCUSSION}

Observations from Table 1 shows that there is not enough data evidence to reject the null hypothesis that true difference in mean value of WBC, Neutrophils and Lymphocytes in both subjects and controls at 0.01 level of significance. This is because the p-values (probabilities) computed from the student's t-test all exceeds 0.01 . The inference here is, therefore, that in each of the solid waste subjects and controls, the baseline haematological values are not significantly different. The inference is supported by the boxplots in Figure 1 since all boxes (top right, top middle and top left) overlap. The baseline haematological study for solid waste disposal workers reviewed slight decreases in the WBC and Neutrophils except for Lymphocytes which was higher in the studied samples than the control samples. The increase observed in lymphocytes values may be due to its involvement in immunological responses as they tend to get involved in a cascade of events which results in inflammation and various pathological conditions such as hypersensitivity, immunosuppression, 
immunomodulation and autoregression on exposure to allergens or environmental pollution (Barbara and Marek, 2012). The Neutrophils count in both studied samples and the control samples were found between the percentage counts with slight increase in the control samples.

Table 1: Baseline haematological values of solid waste disposal subjects and controls.

\begin{tabular}{llllllll}
\hline Haematological Parameters & \multicolumn{2}{l}{ Subjects $(\mathbf{n}-\mathbf{2 7})$} & \multicolumn{2}{l}{ Control $(\mathbf{n}=\mathbf{1 6})$} & & \\
& No. & Mean \pm SD & No. & Mean \pm SD & df & T & Probability \\
\hline WBC $\left(11 \times 10^{-4}\right)$ & 27 & $5.98 \pm 2.63$ & 16 & $7.23 \pm 2.38$ & 41 & -1.558 & $>0.01$ \\
Neutrophils (\%) & 27 & $58.11 \pm 14.86$ & 16 & $61.50 \pm 11.77$ & 41 & -0.778 & $>0.01$ \\
Lymphocytes (\%) & 27 & $43.67 \pm 14.96$ & 16 & $37.93 \pm 10.93$ & 41 & 1.377 & $>0.01$ \\
\hline
\end{tabular}

In Table 2, since p-values (probabilities) for all liver function parameters are greater than 0.01 , there is not enough data evidence to reject the null hypotheses that true difference in mean values of the parameters for solid waste disposal subjects and controls is zero. The implication here is that none of the parameters have significantly different subject and control values. The liver function test across the experimental and control samples showed no significant difference. The result of total protein which showed no significant difference correspond with those of liver function tests as remarkable increase in circulation of protein in the blood which is atypical of liver malfunctioning would have also suggested increased activities of alanine amino transferase (ALT), Aspartate amino transferase (AST) and Alkaline Phosphatase (ALP). The results suggests that exposure of the roadside workers to allergens may have been countered by regulatory effect of their immune system. Also functioning of the liver may not be impaired until after a long period of constant exposure to pollutants, allergens and heavy metals.

Table 2: Baseline liver function values of solid waste disposal subjects and controls

\begin{tabular}{llllllll}
\hline & \multicolumn{2}{l}{ Subjects $(\mathbf{n}-27)$} & \multicolumn{2}{l}{ Control $\mathbf{( n = 1 6 )}$} & \multicolumn{2}{l}{} \\
Liver Function Tests & No. & Mean \pm SD & \multicolumn{2}{l}{ Mean \pm SD } & df & T & Probability \\
\hline ALT $(0-15 i u / l)$ & 27 & $4.41 \pm 1.84$ & No. & Mean \pm SD & 41 & -1.096 & $>0.01$ \\
AST(0-20iu/l) & 27 & $6.46 \pm 2.60$ & 16 & $7.51 \pm 2.88$ & 41 & -1.222 & $>0.01$ \\
ALP $(10-160 u / l)$ & 27 & $23.36 \pm 8.84$ & 16 & $25.08 \pm 9.65$ & 41 & -0.596 & $>0.01$ \\
ALB $(35-50 i u / l)$ & 27 & $41.0 \pm 3.51$ & 16 & $40.81 \pm 3.66$ & 41 & 0.167 & $>0.01$ \\
T/Protein(50-80iu/l) & 27 & $63.49 \pm 7.16$ & 16 & $60.25 \pm 4.67$ & 41 & 1.483 & $>0.01$ \\
T/BIL $(0-20 i u / l)$ & 27 & $6.33 \pm 4.85$ & 16 & $6.42 \pm 4.67$ & 41 & -0.061 & $>0.01$ \\
C/BIL(0-20iu/l) & 27 & $0.82 \pm 0.52$ & 16 & $1.06 \pm 0.60$ & 41 & -1.367 & $>0.01$ \\
\hline
\end{tabular}

All of the parameters have higher location value (mean) and variability (standard deviation) values than others; these values are just descriptive summaries representing centre of the data values in the liver function parameters and their corresponding spreads from the central values. The t-test has revealed that they may look different but their true differences are zeroes.
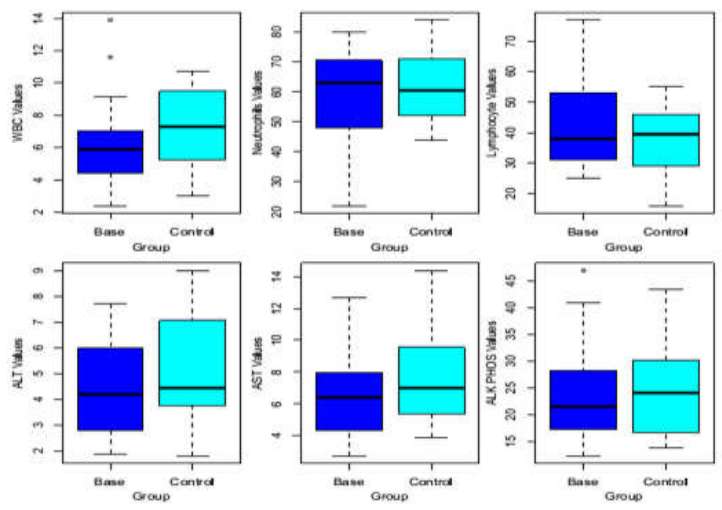

Fig 2: Boxplot showing median deposits of baseline haematological and liver function parameters values in solid waste disposal subjects.
On disposal subjects and controls, the implication here is that none of the parameters has significantly different subject and control values. Summaries in Figure 2 further support these inferences. The studied sites showed varied concentrations of heavy metals ranging from $49.5 \mathrm{mg} / \mathrm{kg}$ to $12.5 \mathrm{mg} / \mathrm{kg}$. Studied site 5 reviewed highest concentration of $\mathrm{Pb}$ metal.

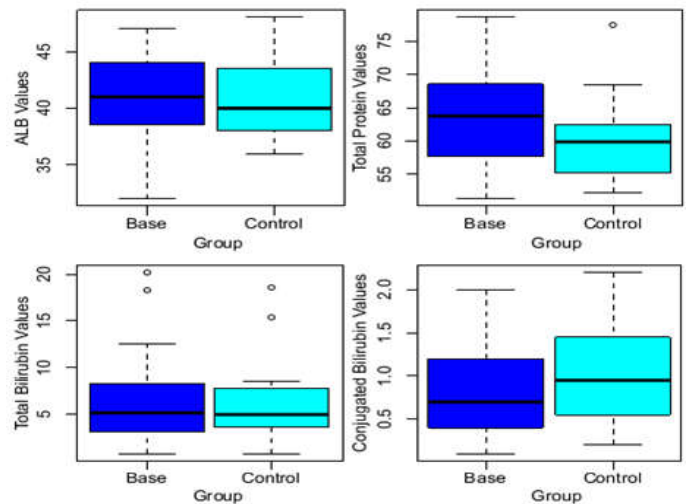

Fig 3: Boxplot showing median deposits of baseline liver function values in solid waste. 
All the metals studied in the samples collected along the major roads and dumpsites were found within the limit of heavy metals for soil by TTLC total threshold limit concentration for hazardous toxic waste (California Department of Toxic substances control). Because we have more than two samples (metals) to compare here and, no doubt, data values under all of them do not have equal variance, we adopted the Kruskal-Wallis rank sum test (Spurrier, 2003) in applying the null hypothesis that there is no statistically detectable difference between median deposit values of the metals in the study area, across all the samples.

\begin{tabular}{lllll} 
& \multicolumn{4}{l}{ Table 3: Average metal deposits. } \\
\hline Sample & $\begin{array}{l}\mathbf{P b} \\
\text { (mg/kg) }\end{array}$ & $\begin{array}{l}\mathbf{C d} \\
\mathbf{( m g} / \mathbf{k g})\end{array}$ & $\begin{array}{l}\mathbf{N i} \\
\mathbf{( m g} / \mathbf{k g})\end{array}$ & $\begin{array}{l}\mathbf{C r} \\
\mathbf{( m g} / \mathbf{k g})\end{array}$ \\
\hline $\mathbf{1}$ & 29.0 & 2.0 & 19.5 & 25.4 \\
$\mathbf{2}$ & 18.0 & 0.5 & 15.0 & 13.7 \\
$\mathbf{3}$ & 29.5 & 2.0 & 15.0 & 12.6 \\
$\mathbf{4}$ & 16.0 & 0.5 & 12.5 & 10.4 \\
$\mathbf{5}$ & 49.5 & 2.0 & 15.5 & 14.6 \\
$\mathbf{6}$ & 12.5 & 1.5 & 11.0 & 15.5 \\
\hline
\end{tabular}

From Table 4, it is evident that there is enough data evidence to reject the null hypothesis of equal median amounts of the four metals deposited in the site across all the six samples since the test p-value 0.0013 is smaller than the significance $\alpha=0.05$. To determine which of the metals have significantly different median deposit for the six samples, we conducted a test of multiple comparisons for median deposits of the four metals. Results of the test are summarized in Table 5. Since critical differences (10.7706) in Table 5 are greater than observed differences between all pairs of the metals except $\mathrm{Cd}-\mathrm{Pb}$, there is enough data evidence to conclude that only Cadmium (Cd) and lead had significantly different average deposit across the six samples in the study location. This inference is further evident in Figure 1. Each box represents five number summaries deposit of each metal type including minimum (inverted T), lower quartile (lower end of box), median (middle tick line), upper quartile (upper end of box) and maximum (T on top of each box) deposit of each metal. All metals whose boxes overlap do not have statistically detectable difference in their deposit while those whose boxes are not overlapping (Cadmium and lead) have statistically detectable median deposit in the study location.

\begin{tabular}{lllll}
\multicolumn{5}{c}{ Table 4: Kruskal-Wallis rank sum test. } \\
\hline Data & Chi-squared & Df & p-value & Decision \\
\hline $\begin{array}{l}\text { Metal } \\
\text { Deposits }\end{array}$ & 15.5558 & 3 & 0.0013 & Reject $\mathrm{H}_{\mathrm{O}}$ \\
\hline
\end{tabular}
different

The least deposited metal was Cadmium (Cd); Chromium (Cr) and Nickel (Ni) had approximately the same average deposit value and the most deposited metal was Lead $(\mathrm{Pb})$. Lead is of great concern because of its bioaccumulation and fat solubility. Lead has affinity for cell membranes and mitochondria oxidative phosphorylations (Suwalsky et al., 2003).

\begin{tabular}{llll}
\multicolumn{2}{c}{ Table 5: } & Post-hoc test for median metal deposit. \\
\hline $\begin{array}{l}\text { Pairs of } \\
\text { Metal }\end{array}$ & $\begin{array}{l}\text { Observed } \\
\text { Difference }\end{array}$ & $\begin{array}{l}\text { Critical } \\
\text { Difference }\end{array}$ & Difference \\
\hline Cd-Cr & 9.9167 & 10.7706 & FALSE \\
$\mathbf{C d - N i}$ & 10.3333 & 10.7706 & FALSE \\
$\mathbf{C d - P b}$ & 15.7500 & 10.7706 & TRUE \\
$\mathbf{C r - N i}$ & 0.4167 & 10.7706 & FALSE \\
$\mathbf{C r - P b}$ & 5.8333 & 10.7706 & FALSE \\
$\mathbf{N i - P b}$ & 5.4167 & 10.7706 & FALSE \\
\hline
\end{tabular}

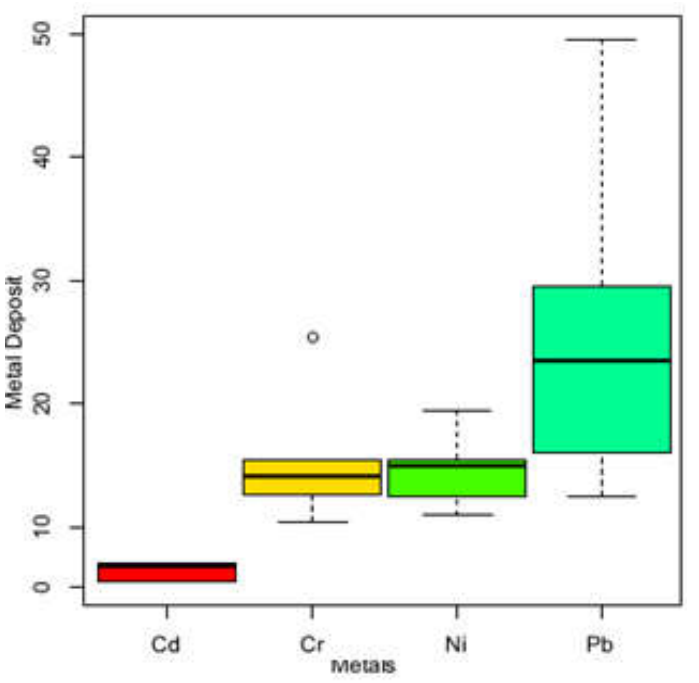

Fig 4: Boxplot showing median deposits of metals for six study samples

From Table 6, there is enough data evidence to reject the null hypothesis of zero true difference in mean baseline Chromium concentration of solid waste disposal subjects and controls since p-value 0.0045 is smaller than the significance level 0.01 . The true difference in mean Baseline Cadmium and Lead concentration of solid waste disposal subjects and controls since their p-values 0.0652 and 0.9427 are bigger than 0.01 .

These inferences are further evident in Figure 4. The lead concentration of the blood of the workers under study was high. The lead in the studied samples could be traced to the lead in the studied sites. Lead metals could be inhaled or ingested as the case may be. The normal human serum lead concentration is under 20 $\mathrm{mg} / \mathrm{L}$. Lead inhaled can cause neurological harm and impair body growth. Higher lead can also cause anaemia (Schwartz et al., 2010). The studied serum showed increase of $\mathrm{Cr}$ in the samples studied as compared to control samples. This may be as a result of the exposure of the workers to the mixed waste. 
Table 6: Baseline heavy metal values of solid waste disposal subjects and controls.

\begin{tabular}{llllllll}
\multicolumn{7}{c}{ Table 6: Baseline heavy metal values of solid waste disposal subjects and controls. } \\
\hline $\begin{array}{l}\text { Metal } \\
\text { Concentration } \\
\left(\mathbf{m g} / \mathbf{l}^{-\mathbf{1}}\right)\end{array}$ & $\begin{array}{l}\text { Subjects }(\mathbf{n}=\mathbf{2 7}) \\
\text { No. }\end{array}$ & $\begin{array}{c}\text { Control } \mathbf{( n = 1 6 )} \\
\text { mean }\end{array}$ SD & No. & mean \pm SD & Df & T & Probability \\
\hline $\mathbf{C r}$ & 27 & $0.700 \pm 1.268$ & 15 & $2.963 \pm 2.531$ & 17.9852 & -3.244 & $0.0045<0.01$ \\
$\mathbf{C d}$ & 27 & $0.241 \pm 0.527$ & 15 & $0.819 \pm 1.069$ & 17.8616 & -7.965 & $0.0652>0.01$ \\
$\mathbf{P b}$ & 27 & $0.226 \pm 0.247$ & 15 & $0.234 \pm 0.388$ & 20.4685 & -0.073 & $0.9427>0.01$ \\
\hline
\end{tabular}
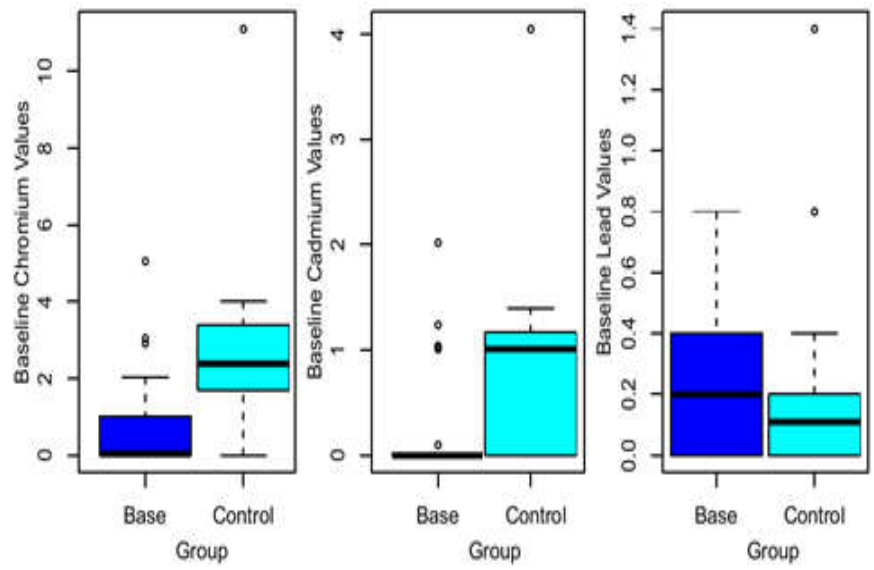

Fig 5: Boxplot showing median deposits of baseline chromium, cadmium and lead concentrations of solid waste disposal subjects and controls.

Conclusion: This study showed the trend in the exposure of waste workers to hazardous substances in the waste collected and pre-disposed areas. Haematological parameters in the subject showed no significant difference when compared to the control samples. This is probably due to the time of exposure to the waste. However, heavy metals concentration in the serum is significant; therefore, suggesting the need for periodic monitoring of the waste workers.

Acknowledgments: The researchers expressed their profound gratitude to the Centre for Ecological, Environmental, Research Management and Studies (CEERMS) Kwara State University, and Ministry of Environment Kwara State for their support in reaching out to the volunteers and obtaining Ethical approval. Our profound gratitude also goes to the TETFUND Research Grant (KWASUNGR/CSP/040914/Vol.2/TETF/0020) of the Federal Republic of Nigeria for the financial support.

\section{REFERENCES}

Babula, P; Adam, V; Opatrilova, R; Zehnalek, J; Havel, L; Kizek. R. (2008). Uncommon heavy metals, metalloids and their plant toxicity: a review, Environ Chem Lett. 6:189-213.

De Miguel, E; Irribarren, I; Chacón, E; Ordoñez, A; Charlesworth, S. (2007). Risk-based evaluation of the exposure of children to trace elements in playgrounds in Madrid (Spain), Chemosphere. 66:505-513.

Amato, F; Pandolfi, M; Viana, M; Querol, X; Alastuey, A; Moreno, T. (2009). Spatial and chemical patterns of PM10 in road dust deposited in urban environment. Atmos Environ. 43:1650-1659.

Faiz, Y; Tufail, M; Javed, MT; Chaudhry, MM; Siddique, N. (2009). Road dust pollution of Cd, $\mathrm{Cu}, \mathrm{Ni}, \mathrm{Pb}$ and $\mathrm{Zn}$ along Islamabad Expressway, Pakistan, Microchem J. 24(2):245-249.

Montagne, D; Cornu, S; Bourennane, H; Baize, D; Ratié, C; King, D. (2007). Effect of agricultural practices on trace-element distribution in soil, Commun Soil Sci. Plan. 38:473-49.

Yang, P; Mao, R; Shao, H; Gao, Y. (2009). The spatial variability of heavy metal distribution in the suburban farmland of Taihang Piedmont Plain, China, C. R. Biologies. 332: 558-566.

Bhargava, AK; Gupta, R; Bhargava, S. (2003). Effect of automobile exhaust on total N, P and heavy metals of road side sugarcane at district Saharanpur, Ad Plant Sci. 16(16): 557-560.

Rakel, RE; Bope, ET. (2005). Conn's Current Therapy. W.B. Saunders Company, Philadelphia, P.A. USA. Pp 465. 
David, TW. (2009). Chemical Allergies, Chemical Sensitivities Journal technology, 12(4): 240-250.

Sezgin, N; Ozcan, HK; Demir, G; Nemlioglu, S; Bayat, C. (2006). Determination of heavy metals in street dust in Istanbul E-5 Highway, Environ Int. 29:797-985.

Patel, K. S; Shukla, A; Tripathi, A. N; Hoffman, P. (2001). Heavy metal concentrations of precipitation in east Madhya Pradesh of India", Water Air Soil Poll, 130:463-468.

Nazzal, Y; Ghrefat, H; Rosen, MA. (2014). Heavy Metals Contamination of Roadside Dusts. Science 8:5, 259-273.

Wachukwu, K; Confidence, U; Eleanya, EU. (2007). Health Impact Assessment of Solid Waste Workers in Port Harcourt, Nigeria. J Appl Sci. 7(22): 3562-3566.

Bada, BS; Amusan, AA; Salami, AT. (2001). Levels of some heavy metals in soil and vegetation along roadsides in Osun State, Nigeria, J. Agric. Environ. 2:271 - 280 .
Barbara, MW; Marek, LK. (2012). Allergens, Air pollutants and Immune System Function in the Era of Global Warming Department of Immunology, Rheumatology and Allergy. Medical University of Lodz, Poland. Pp 267.

Spurrier, JD. (2003). On the null distribution of the Kruskal-Wallis statistics. J. Nonparametric Statistics. 15(6):685-691.

Suwalsky, M; Villena, F; Norris, B; Cuevas, YF; Sotomayor, CP; Zatta, P. (2003). "Effect of Lead on the Human Erythrocyte Membrane and Molecular Models" J. Inorg. Biochem. 97:308313.

Schwartz, B.S; Caffo, B; Stewart, WF; Hedlin, H; James, BD; Yousem, D; Davatzikos, C. (2010). Evaluatuion of cumulative lead dose and longitudinal changes in structural MRI in former organolead workers. J Occup. Environ. 52 (4):407. 